Research Paper

\title{
Pre-treatment serum alkaline phosphatase and lactate dehydrogenase as prognostic factors in triple negative breast cancer
}

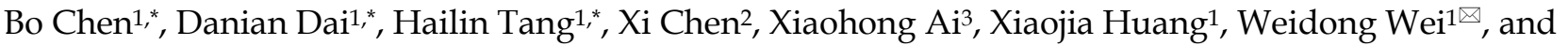 \\ Xiaoming $\mathrm{Xie}^{1 \times}$ \\ 1. Department of Breast Oncology, Sun Yat-Sen University Cancer Center, State Key Laboratory of Oncology in South China, Collaborative Innovation Center \\ for Cancer Medicine, Guangzhou, China. \\ 2. Department of Anatomy, Medical College, University of South China, Hengyang, Hunan Province, China. \\ 3. Department of Radiotherapy, The First Affiliated Hospital, University of South China, Hengyang, Hunan Province, China. \\ * B. Chen, D. Dai and H. Tang contributed equally to this work. \\ $\square$ Corresponding authors: Xiaoming Xie and Weidong Wei, Department of Breast Oncology, Sun Yat-Sen University Cancer Center, 651 East Dongfeng Road, \\ Guangzhou, 510060, People's Republic of China; Phone: 86-20-87343806; Fax: 86-20-87343805; E-mail: xiexm@sysucc.org.cn, weiwd@sysucc.org.cn.
}

( ) Ivyspring International Publisher. Reproduction is permitted for personal, noncommercial use, provided that the article is in whole, unmodified, and properly cited. See http://ivyspring.com/terms for terms and conditions.

Received: 2016.06.28; Accepted: 2016.09.17; Published: 2016.11.25

\begin{abstract}
Background: Serum parameters as prognostic parameters are studied widely. We aim to examine the prognostic significance of the serum alkaline phosphatase (ALP) level and lactate dehydrogenase (LDH) level in triple negative breast cancer (TNBC).

Methods: Total of 253 TNBC patients from Sun Yat-sen University Cancer Center who underwent treatment between January 2004 and December 2009 was conducted in this retrospective study. Before treatment serum ALP and LDH levels were routinely measured. We use the receiver operating characteristic (ROC) curve analysis to estimate the cutoff value of serum ALP and LDH levels. The Kaplan-Meier method and multivariable Cox regression analysis were used for Disease free survival (DFS) and overall survival (OS) assessed.

Results: The ROC curves determined that the optimum cutoff point for ALP and LDH were 66.5u/L and 160.5u/L, respectively. The elevated ALP and LDH were both significantly associated with decreased DFS and OS (both $P<0.001$ ). In addition, the entire cohort was stratified into three subgroups basis of ALP levels and LDH levels. TNBC Patients who with ALP $>66.5 \mathrm{u} / \mathrm{L}$ and $\mathrm{LDH}>160.5 \mathrm{u} / \mathrm{L}$ had the worst DFS and OS (both $\mathrm{P}<0.001$ ). In TNBC patients, univariate and multivariate Cox regression analyses conformed ALP and LDH were independent unfavorable prognostic factors for DFS and OS.

Conclusions: The serum levels of ALP and LDH before treatment are independent prognostic parameters and may serve as complement to help predict survival in TNBC.
\end{abstract}

Key words: Alkaline phosphatase, Lactate dehydrogenase, Triple negative breast cancer, Prognostic factor, Biomarker.

\section{Introduction}

Cancer is an increasingly global problem and breast cancer is the main cause of cancer death in women worldwide[1, 2]. It is generally known that breast cancer has various genetic alterations and it to be classified into different molecular subtypes. As a refractory subtype of breast cancer, Triple negative breast cancer (TNBC) is a heterogeneous clinicopathological cancer and shows high recurrence rate and poor prognosis[3]. About $15 \%$ to $20 \%$ breast cancer patients are TNBC[4]. It has attracted increasing clinical and basic scientific research attention on the prognostic factors for patients with 
TNBC.

A valuable prognostic factor should be accurate and reproducible, but also easily performed. In recent years, many studies focus on blood parameters and serum parameters that may be prognostic parameters in cancer. An increasing body of evidence has confirmed the utility of blood parameters and serum parameters in predicting TNBC patient prognosis. For example, increased pre-treatment neutrophil to lymphocyte ratio (NLR) may be associated with poor prognosis in early TNBC patients [5]. The high fibrinogen level before operative was a risk factor for triple negative breast cancer and some other breast cancer subtypes. [6]. Here, we concern about two routinely tested serums biochemical index alkaline phosphatase (ALP) and lactate dehydrogenase (LDH). ALP is a hydrolase enzyme which responsible for removing phosphate groups. $\mathrm{LDH}$ plays a vital role in the conversion of pyruvate to lactate. Both of them are serum enzymes, which have been found to have prognostic value in several malignancies. According to previously studies, in some kinds of cancer, the elevation of ALP or LDH might indicate a heavy tumor burden and tumor metastasis. High ALP level was reported to be related with worse prognosis in colorectal cancer [7], nasopharyngeal carcinoma [8], prostate cancer[9], and esophageal squamous cell carcinoma[10]. Serum LDH level was demonstrated to be a prognostic factor in nasopharyngeal carcinoma[11], lymphoma[12], small cell lung cancer[13], myeloma[14] and prostate cancer[15]. However, the prognosis value of serum ALP and $\mathrm{LDH}$ in TNBC has remained unclear.

In this retrospectively study, we evaluated serum ALP and serum LDH levels in 253 TNBC patients, and correlated the levels of ALP and LDH to the outcomes of the TNBC patients.

\section{Materials and Methods}

\section{Patients}

This study was conducted female patients who with histological diagnosed of triple-negative breast cancer between January 1, 2004 and December 31, 2009 in Sun Yat-sen University Cancer Center (SYSUCC). TNBC was defined as breast cancer with negative expression of Estrogen receptor (ER-), progesterone receptor (PR-), and human epidermal growth factor receptor 2 (HER-2-). ER, PR, and HER-2 analyses were performed via immunohistochemistry (IHC). ER- or PR- was defined as less than $1 \%$ of positive ER or PR expression cells. Because lacking of fluorescence in situ hybridization data, HER-2 immunohistochemical scores of $0 / 1+$ were including as HER-2 negative. A Patient was excluded from the study: 1) without follow-up; 2) with previous or coexisting cancers; 3) Declined treatment; 4) with active infections; 5) with liver disease or heart disease; 6) without available data of ALP and LDH before treatment. All patients were followed up to November 27, 2015 or until death. Sun Yat-sen University Cancer Center Institute Research Ethics Committee approved this retrospective study, and all enrolled patients had written informed consent. The methods were in accordance with the approved guidelines.

\section{Clinical data collection}

Before patients received prior treatment, baseline serum ALP and LDH had been routinely determined by Hitachi Automatic Analyzer 7600-020 (Hitachi, Tokyo, Japan). Clinical and histopathological data were collected through database chart review. Disease staging were determined according to the American Joint Committee on Cancer (AJCC) 7th Edition by TNM staging system. Patients were followed up by the Follow-up Department through outpatient medical records or telephone.

\section{Statistical analyses}

A $P$ value of $<0.05$ was considered statistically significant. SPSS for Windows version 20.0 (SPSS, Chicago, IL, USA) was used to analyze all of the statistical data. Optimal cutoff values for the ALP and $\mathrm{LDH}$ were calculated by applying receiver operating curve (ROC) analysis. Univariate analyses with the Chi-squared test or Fisher's exact test were performed to investigate the associations of ALP or LDH level with clinicopathologic variables. Overall survival (OS) and Disease-free survival (DFS) were calculated from the initial treatment. Survival curves were calculated by the Kaplan-Meier and compared with the log-rank test. Univariate and multivariate analyses (Cox proportional hazards regression model) examined prognostic factors. Variables which $P<0.05$ in the univariate analysis were entered into the multivariate analysis.

\section{Result}

\section{Patient characteristics and ROC Analysis}

We identified 502 female patients who were histopathologically diagnosed TNBC in SYSUCC. 253 female patients were enrolled after eligibility review. The reasons for the excluded patients are summarized in Fig.1. The median age of these patients was 47 years (range, 22-79 years), and their median follow-up time was 89 months (range, 2-143 months [censored]). At the end of this study, $45.8 \%(116 / 253)$ of the patients experienced local/distant recurrence, and $43.1 \%$ $(109 / 253)$ died. Invasive ductal carcinoma was the 
predominant type (93.3\%). Only 12 patients (4.7\%) were diagnosed with invasive lobular carcinoma and 5 patients $(2.0 \%)$ were diagnosed with intraductal carcinoma in situ. Of 253 consecutive patients, all of them received surgical treatment. 231 patients (91.3\%) received neoadjuvant/ adjuvant chemotherapy and $54(21.3 \%)$ patients received radiotherapy. Using the overall survival as an endpoint, the optimal cutoff value of pre-treatment serum ALP and LDH level were determined by ROC curve analysis. The area under the ROC curve was $0.602(95 \% \mathrm{CI}, 0.531-0.673)$ for ALP and 0.635 (95\%CI, 0.565-0.705) for $\mathrm{LDH}$ (Fig.2). With the highest Youden's index, the cutoff point for pre-treatment serum ALP and LDH levels were $66.5 \mathrm{u} / \mathrm{L}$ and $160.5 \mathrm{u} / \mathrm{L}$, respectively. Then, 76 patients $(30.0 \%$ ) with ALP $>66.5 \mathrm{u} / \mathrm{L}$ and 177 patients $(70.0 \%)$ with ALP $\leq 66.5 \mathrm{u} / \mathrm{L}$ were classified into an ALP-high and ALP-low group, respectively. Meanwhile, by the cutoff point for LDH, 132 patients (52.2\%) were classified into a LDH-high group (LDH $>160.5 \mathrm{u} / \mathrm{L})$ and 121 patients $(47.8 \%)$ were classified into a LDH-low group (LDH $\leq 160.5 \mathrm{u} / \mathrm{L})$. To our best knowledge, this is the first report looking specifically at the predictive value of ALP and LDH in TNBC.

\section{Relationships between ALP or LDH and other clinical characteristics}

Correlations between pre-treatment serum ALP or LDH level and clinicopathological parameters are shown in Table 1. An obvious difference between ALP -high group and ALP -low group in the age, menstrual status (both $P<0.001$ ) and lymph node (LN) Infiltrated $(P=0.001)$; No significant difference in the Body Mass Index (BMI), tumor size, tumor status, TNM staging, LN Infiltrated and histological

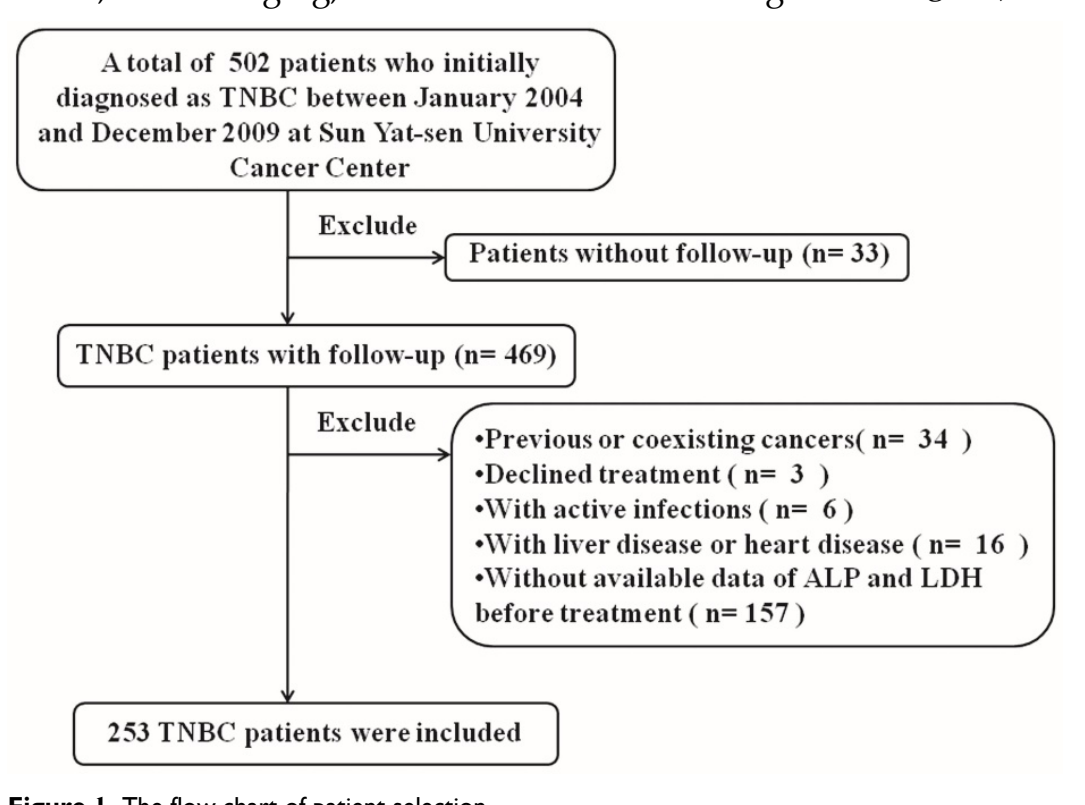

Figure 1. The flow chart of patient selection. grade $(P>0.05)$. At the same time, we found that a higher level of LDH was related to the age, menstrual status (both $P<0.001)$, BMI $(P=0.007)$ and $\mathrm{LN}$ Infiltrated $(P=0.001)$. No correlation was observed between LDH level and other clinical characteristics $(P>0.05)$.

\section{Prognostic significance of ALP and LDH in TNBC}

A Kaplan-Meier survival analysis was conducted to analyze the significance of ALP and $\mathrm{LDH}$ in terms of clinical prognosis, (Table 2). Expectedly, the results showed that the ALP-high group patients presented shorter mean months of DFS and OS than the ALP -low group patients $(P<0.001$ for DFS; Fig. 3A, $P<0.001$ for OS; Fig. 3D). We also observed that higher level of $\mathrm{LDH}$ was associated with a lower disease-free survival rate and a lower overall survival rate $(P<0.001$ for DFS; Fig. 3B, $P$ $<0.001$ for OS; Fig. 3E). In addition, we divided the patients into following three subgroups on the basis of ALP levels $(\leq 66.5 \mathrm{u} / \mathrm{L}$ or $>66.5 \mathrm{u} / \mathrm{L})$ and LDH levels $(\leq 160.5 \mathrm{u} / \mathrm{L}$ or $>160.5 \mathrm{u} / \mathrm{L})$. Group I: ALP $(\leq 66.5 \mathrm{u} / \mathrm{L})$ and LDH $(\leq 160.5 \mathrm{u} / \mathrm{L})$ both in a lower level, Group III: ALP $(>66.5 \mathrm{u} / \mathrm{L})$ and LDH $(>160.5 \mathrm{u} / \mathrm{L})$ both in a higher level, and the rest of patients all in Group II. There were $102(40.3 \%), 94(37.2 \%)$, and 57 (22.5\%) patients were classified into the three groups respectively. Among the three groups, in group III, patients with a higher level of ALP and LDH had the worst DFS and OS. These results indicated that the pre-treatment serum ALP and LDH levels were significantly associated with the TNBC patients DFS and OS $(P<0.001$ for DFS; Fig. $3 C, P<0.001$ for OS; Fig. 3F).

Based on above analyses, high ALP and high LDH levels were significantly associated with a higher recurrence and mortality in TNBC. Next, in Univariate Cox proportional hazard regression analysis revealed that tumor status, lymph node metastasis, histological grade, ALP levels and LDH levels were predictive factors of prognosis for DFS and OS in TNBC patients. Multivariate regression analysis confirmed that tumor status, lymph node metastasis, ALP levels (HR $1.826(95 \%$ CI $1.179-2.828), P=0.007$ for DFS and HR 1.772(95 \% CI 1.164-2.698), $P=0.008$ for OS) and LDH levels (HR $1.577(95 \%$ CI $1.027-2.422), P=0.038$ for DFS and HR 1.700(95 \% CI 1.126-2.567), $P=0.012$ for OS) were independent prognostic factors (Table 3 ). 


\section{Discussion}

TNBC is a diverse and heterogeneous group of breast cancer simply defined by the absence of ER, PR and HER2 amplification[16]. Besides the TNM stage, tremendous studies have been carried out on identifying reliable prognostic factors in TNBC. In recent years, some studies have demonstrated the prognostic value of blood parameters and serum parameters, which are inexpensive, accurate, identified by easy method of detection and validated. Although underlying mechanism is unclear, increased pretreatment blood parameters and serum parameters have been confirmed to associate with prognosis of several cancers, such as neutrophil-to-lymphocyte ratio (NLR)[17, 18], lymphocyte-to-monocyte ratio (LMR), monocyte count[19], platelet-to-lymphocyte ratio (PLR)[20], fibrinogen[21] haptoglobin [22] and C-reactive protein[23]. The serum levels of ALP and $\mathrm{LDH}$ are routine diagnostic tests in clinical laboratories. In this paper, we focus on the pre-treatment serum ALP and LDH levels and explore the prognostic value of them in TNBC patients.

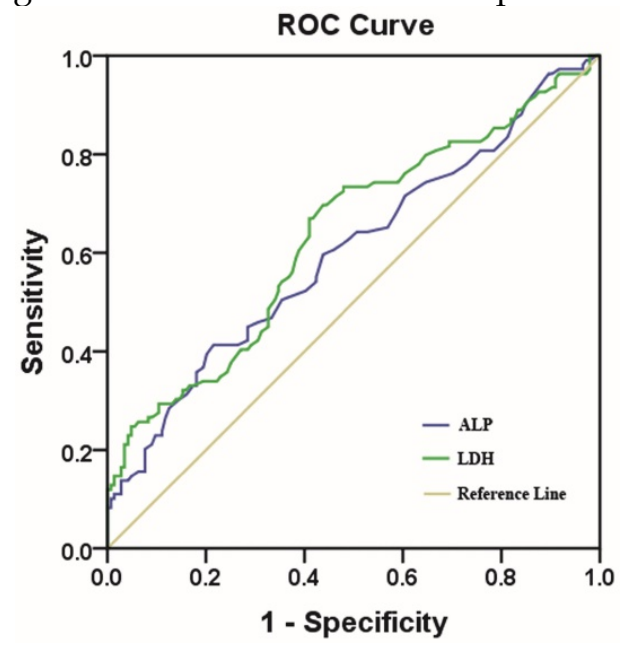

Figure 2. The cutoff value of the pre-treatment serum ALP and LDH levels. Notes: ALP with an AUC of $60.2 \%$ (sensitivity of $41.3 \%$ and specificity of $78.5 \%$ ); LDH with an AUC of $63.5 \%$ (sensitivity of $67.0 \%$ and a specificity of 59.0\%). Abbreviations: AUC, area under the curve.

Table 1. Correlation between the clinicopathological variables and ALP or LDH in triple negative breast cancer cases.

\begin{tabular}{|c|c|c|c|c|c|c|c|}
\hline \multirow[t]{2}{*}{ Variables } & \multirow[t]{2}{*}{ Cases $(n=253)$} & \multicolumn{2}{|c|}{ ALP } & \multicolumn{4}{|c|}{ LDH } \\
\hline & & $\begin{array}{l}\text { Low } \\
\text { No. (\%) }\end{array}$ & $\begin{array}{l}\text { High } \\
\text { No. (\%) }\end{array}$ & $P$ value & $\begin{array}{l}\text { Low } \\
\text { No. (\%) }\end{array}$ & $\begin{array}{l}\text { High } \\
\text { No. }(\%)\end{array}$ & $P$ value \\
\hline Age (years) & & & & $<0.001^{*}$ & & & $<0.001^{*}$ \\
\hline$\leq 50$ & 166 & $131(78.9 \%)$ & $35(21.1 \%)$ & & $93(56.0 \%)$ & $73(44.0 \%)$ & \\
\hline$>50$ & 87 & $46(52.9 \%)$ & $41(47.1 \%)$ & & $28(32.2 \%)$ & $59(67.8 \%)$ & \\
\hline menopause & & & & $<0.001^{*}$ & & & $<0.001^{*}$ \\
\hline no & 103 & $54(52.4 \%)$ & $49(47.6 \%)$ & & $34(33.0 \%)$ & $69(67.0 \%)$ & \\
\hline yes & 150 & $123(82.0 \%)$ & $27(18.0 \%)$ & & $87(58.0 \%)$ & $63(42.0 \%)$ & \\
\hline BMI & & & & 0.096 & & & $0.007^{*}$ \\
\hline$\leq 25$ & 194 & $141(72.7 \%)$ & $53(27.3 \%)$ & & $102(52.6 \%)$ & $92(47.4 \%)$ & \\
\hline$>25$ & 59 & $36(61.0 \%)$ & $23(39.0 \%)$ & & $19(32.2 \%)$ & $40(67.8 \%)$ & \\
\hline Tumor size & & & & 0.632 & & & 0.120 \\
\hline$\leq 2.0 \mathrm{~cm}$ & 82 & $59(72.0 \%)$ & $23(28.0 \%)$ & & $45(54.9 \%)$ & $37(45.1 \%)$ & \\
\hline$>2.0 \mathrm{~cm}$ & 171 & $118(69.0 \%)$ & $53(31.0 \%)$ & & $76(44.4 \%)$ & $95(55.6 \%)$ & \\
\hline Tumor status & & & & 0.522 & & & $0.020^{*}$ \\
\hline $\mathrm{T} 1$ & 72 & $53(73.6 \%)$ & $19(26.4 \%)$ & & $45(62.5 \%)$ & $27(37.5 \%)$ & \\
\hline $\mathrm{T} 2$ & 141 & $97(68.8 \%)$ & $44(31.2 \%)$ & & $60(42.6 \%)$ & $81(57.4 \%)$ & \\
\hline T3 & 21 & $16(76.2 \%)$ & $5(23.8 \%)$ & & $10(47.6 \%)$ & $11(52.4 \%)$ & \\
\hline $\mathrm{T} 4$ & 19 & $11(57.9 \%)$ & $8(42.1 \%)$ & & $6(31.6 \%)$ & $13(68.4 \%)$ & \\
\hline TNM staging & & & & 0.063 a & & & 0.057 a \\
\hline I & 51 & $41(80.4 \%)$ & $10(19.6 \%)$ & & $33(64.7 \%)$ & $18(35.3 \%)$ & \\
\hline II & 127 & $91(71.7 \%)$ & $36(28.3 \%)$ & & $56(44.1 \%)$ & $71(55.9 \%)$ & \\
\hline III & 67 & $39(58.2 \%)$ & $28(41.8 \%)$ & & $29(43.3 \%)$ & $38(56.7 \%)$ & \\
\hline IV & 8 & $6(75.0 \%)$ & $2(25.0 \%)$ & & $3(37.5 \%)$ & $5(62.5 \%)$ & \\
\hline LN infiltrated & & & & $0.001^{*}$ & & & $0.001^{*}$ \\
\hline No & 131 & $104(79.4 \%)$ & $27(20.6 \%)$ & & $73(55.7 \%)$ & $58(44.3 \%)$ & \\
\hline Yes & 122 & $73(59.8 \%)$ & $49(40.2 \%)$ & & $48(39.3 \%)$ & $74(60.7 \%)$ & \\
\hline Histological grade & & & & 0.154 a & & & 0.073 a \\
\hline G1 & 3 & $3(100.0 \%)$ & $0(0.0 \%)$ & & $0(0.0 \%)$ & $3(100.0 \%)$ & \\
\hline G2 & 124 & $92(74.2 \%)$ & $32(25.8 \%)$ & & $66(53.2 \%)$ & $58(46.8 \%)$ & \\
\hline G3 & 126 & $82(65.1 \%)$ & $44(34.9 \%)$ & & $55(43.7 \%)$ & $71(56.3 \%)$ & \\
\hline Chemotherapy & & & & 0.244 & & & 0.116 \\
\hline no & 22 & $13(59.1 \%)$ & $9(40.9 \%)$ & & $7(31.8 \%)$ & $15(68.2 \%)$ & \\
\hline yes & 231 & $164(71.0 \%)$ & $67(29.0 \%)$ & & $114(49.4 \%)$ & $117(50.6 \%)$ & \\
\hline Radiotherapy & & & & 0.941 & & & 0.504 \\
\hline no & 199 & $139(69.8 \%)$ & $60(30.2 \%)$ & & $93(46.7 \%)$ & $106(53.3 \%)$ & \\
\hline yes & 54 & $38(70.4 \%)$ & $16(29.6 \%)$ & & $28(51.9 \%)$ & $26(48.1 \%)$ & \\
\hline
\end{tabular}


Table 2. The DFS and OS of TNBC patients according to levels of ALP, LDH, and ALP\&LDH.

\begin{tabular}{|c|c|c|c|c|c|c|c|}
\hline \multirow[t]{2}{*}{ Variable } & \multirow[t]{2}{*}{ Case } & \multicolumn{3}{|c|}{ DFS (months) } & \multicolumn{3}{|c|}{ OS (months) } \\
\hline & & Mean \pm SE & Median & P-value & Mean $\pm \mathrm{SE}$ & Median & P-value \\
\hline Total & 253 & $93.2 \pm 3.5$ & NR & & $104.0 \pm 3.0$ & 136.4 & \\
\hline ALP & & & & $<0.001^{*}$ & & & $<0.001^{*}$ \\
\hline Low group & & $102.1 \pm 3.8$ & NR & & $112.1 \pm 3.2$ & NR & \\
\hline High group & & $71.3 \pm 6.7$ & 44.2 & & $85.0 \pm 6.0$ & 88.0 & \\
\hline LDH & & & & $<0.001^{*}$ & & & $<0.001^{*}$ \\
\hline Low group & & $108.6 \pm 4.5$ & NR & & $116.6 \pm 3.9$ & NR & \\
\hline High group & & $78.6 \pm 4.9$ & 62.5 & & $92.3 \pm 4.3$ & 99.3 & \\
\hline ALP\&LDH & & & & $<0.001^{*}$ & & & $<0.001^{*}$ \\
\hline Group I & & $111.1 \pm 4.7$ & NR & & $119.8 \pm 3.9$ & NR & \\
\hline Group II & & $90.9 \pm 5.6$ & 98.9 & & $100.7 \pm 4.8$ & 126.4 & \\
\hline Group III & & $63.4 \pm 7.4$ & 39.9 & & $80.3 \pm 6.8$ & 62.5 & \\
\hline
\end{tabular}

Abbreviations: NR not reached.

${ }^{*} \mathrm{P}<0.05$, statistically significant.

Table 3. DFS and OS in triple negative breast cancer patients by univariate and multivariate analyses

\begin{tabular}{|c|c|c|c|c|c|c|c|c|}
\hline \multirow{3}{*}{ Variables } & \multicolumn{4}{|c|}{ Overall Survival } & \multicolumn{4}{|l|}{ Disease-free Survival } \\
\hline & \multicolumn{2}{|c|}{ Univariate analysis } & \multicolumn{2}{|c|}{ Multivariate analysis } & \multicolumn{2}{|l|}{ Univariate analysis } & \multicolumn{2}{|c|}{ Multivariate analysis } \\
\hline & $\mathrm{HR}(95 \% \mathrm{CI})$ & $\mathrm{p}$ value & $\mathrm{HR}(95 \% \mathrm{CI})$ & $\begin{array}{l}\mathrm{p} \\
\text { value }\end{array}$ & $\mathrm{HR}(95 \% \mathrm{CI})$ & $\mathrm{p}$ value & $\mathrm{HR}(95 \% \mathrm{CI})$ & $\mathrm{p}$ value \\
\hline $\begin{array}{l}\text { Age (years) }(\leq 50 \\
\text { vs. }>50)\end{array}$ & $1.268(0.862-1.866)$ & 0.229 & & & $1.296(0.892-1.883)$ & 0.174 & & \\
\hline $\begin{array}{l}\text { Menopause (no } \\
\text { vs. yes) }\end{array}$ & $1.046(0.713-1.533)$ & 0.820 & & & $1.022(0.706-1.481)$ & 0.907 & & \\
\hline $\begin{array}{l}\text { Tumor Size } \\
(\leq 2.0 \mathrm{~cm} \text { vs. } \\
>2.0 \mathrm{~cm})\end{array}$ & $1.468(0.955-2.257)$ & 0.080 & & & $1.514(0.999-2.295)$ & 0.050 & & \\
\hline \multicolumn{9}{|l|}{ Tumor status } \\
\hline $\mathrm{T} 1$ & 1 (Reference) & & 1 (Reference) & & 1 (Reference) & & 1 (Reference) & \\
\hline $\mathrm{T} 2$ & $1.784(1.067-2.983)$ & $0.027^{*}$ & $1.543(0.910-2.615)$ & 0.107 & $1.779(1.088-2.907)$ & $0.022^{*}$ & $1.515(0.915-2.506)$ & 0.106 \\
\hline T3 & $2.927(1.443-5.935)$ & $0.003^{*}$ & $2.303(1.067-4.971)$ & $0.034^{*}$ & $2.879(1.441-5.753)$ & $0.003^{*}$ & $2.149(1.012-4.562)$ & $0.046^{*}$ \\
\hline $\mathrm{T} 4$ & $5.308(2.687-10.487)$ & $<0.001^{*}$ & $4.135(1.974-8.661)$ & $\begin{array}{l}<0.001 \\
*\end{array}$ & $5.744(2.981-11.066)$ & $<0.001^{*}$ & $4.576(2.268-9.236)$ & $<0.001^{*}$ \\
\hline \multicolumn{9}{|l|}{$\begin{array}{l}\text { Lymph node } \\
\text { metastasis }\end{array}$} \\
\hline No & 1 (Reference) & & 1 (Reference) & & 1 (Reference) & & 1 (Reference) & \\
\hline N1 & $1.536(0.942-2.505)$ & 0.086 & $0.959(0.570-1.612)$ & 0.874 & $1.372(0.856-2.200)$ & 0.189 & $0.856(0.518-1.414)$ & 0.544 \\
\hline N2 & $3.219(1.999-5.182)$ & $<0.001^{*}$ & $1.885(1.112-3.196)$ & $0.019^{*}$ & $3.125(1.974-4.948)$ & $<0.001^{*}$ & $1.879(1.130-3.123)$ & $0.015^{*}$ \\
\hline N3 & $6.426(3.327-12.413)$ & $<0.001^{*}$ & $4.724(2.400-9.299)$ & $\begin{array}{l}<0.001 \\
*\end{array}$ & $4.862(2.554-9.254)$ & $<0.001^{*}$ & $3.581(1.853-6.920)$ & $<0.001^{*}$ \\
\hline \multicolumn{9}{|l|}{$\begin{array}{l}\text { Histological } \\
\text { grade }\end{array}$} \\
\hline $\mathrm{G} 1+\mathrm{G} 2$ & 1 (Reference) & & 1 (Reference) & & 1 (Reference) & & 1 (Reference) & \\
\hline G3 & $1.839(1.249-2.708)$ & $0.002^{*}$ & $1.440(0.958-2.164)$ & 0.079 & $1.837(1.263-2.670)$ & $0.001^{*}$ & $1.417(0.956-2.102)$ & 0.082 \\
\hline BMI ( $\leq 25$ vs. $>25)$ & $1.090(0.705-1.686)$ & 0.697 & & & $1.229 \quad(0.815-1.855)$ & 0.325 & & \\
\hline $\begin{array}{l}\text { ALP (low vs. } \\
\text { high) }\end{array}$ & $2.126(1.451-3.117)$ & $<0.001^{*}$ & $1.826(1.179-2.828)$ & $0.007^{*}$ & 2.152(1.484-3.121) & $<0.001^{*}$ & $1.772(1.164-2.698)$ & $0.008^{*}$ \\
\hline $\begin{array}{l}\text { LDH (low vs. } \\
\text { high) } \\
{ }^{*} \mathrm{P}<0.05 \text {, statistic }\end{array}$ & $\begin{array}{l}\text { 2.191(1.469-3.269) } \\
\text { ally significant. }\end{array}$ & $<0.001^{*}$ & $1.577(1.027-2.422)$ & $0.038^{*}$ & $2.286(1.554-3.364)$ & $<0.001^{*}$ & $1.700(1.126-2.567)$ & $0.012^{*}$ \\
\hline
\end{tabular}


$\mathbf{A}$

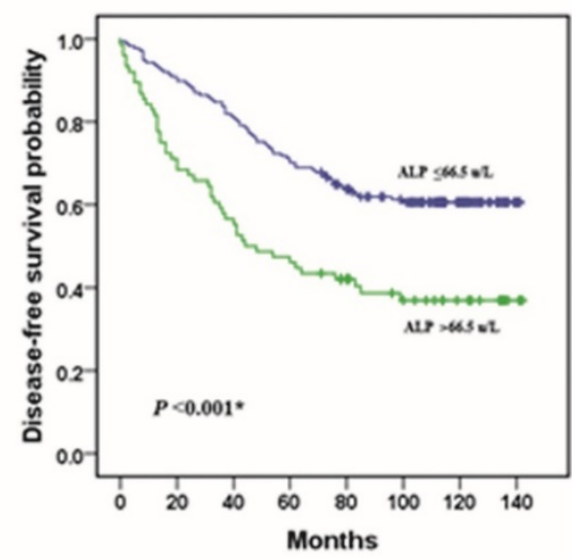

B

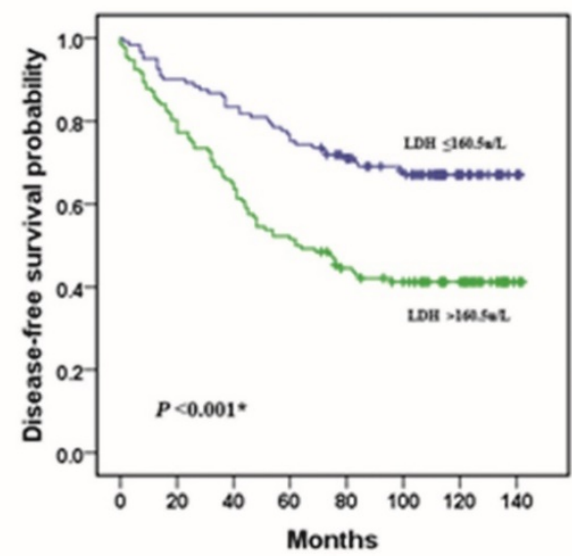

$\mathrm{C}$

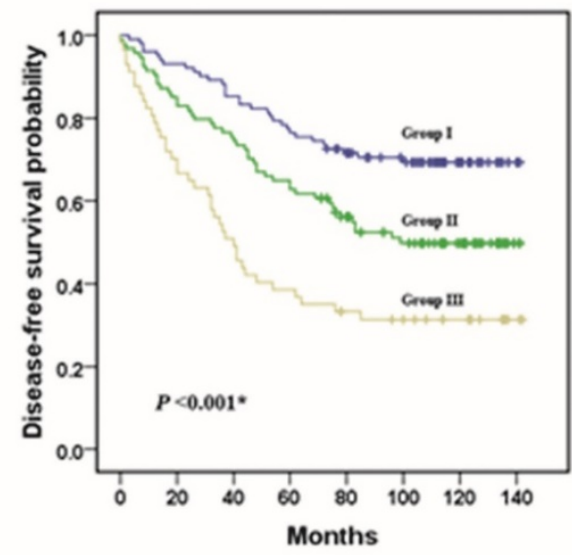

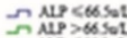

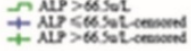
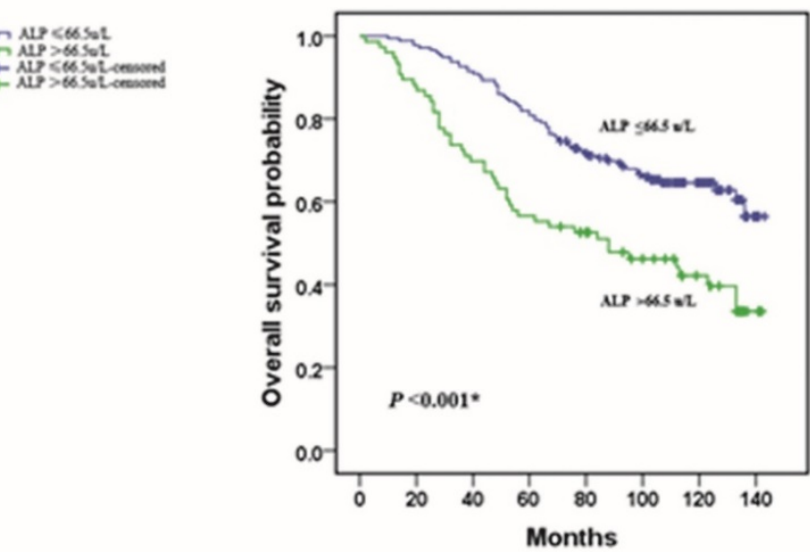

I) $\mu$ P $<606502$

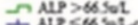

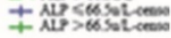
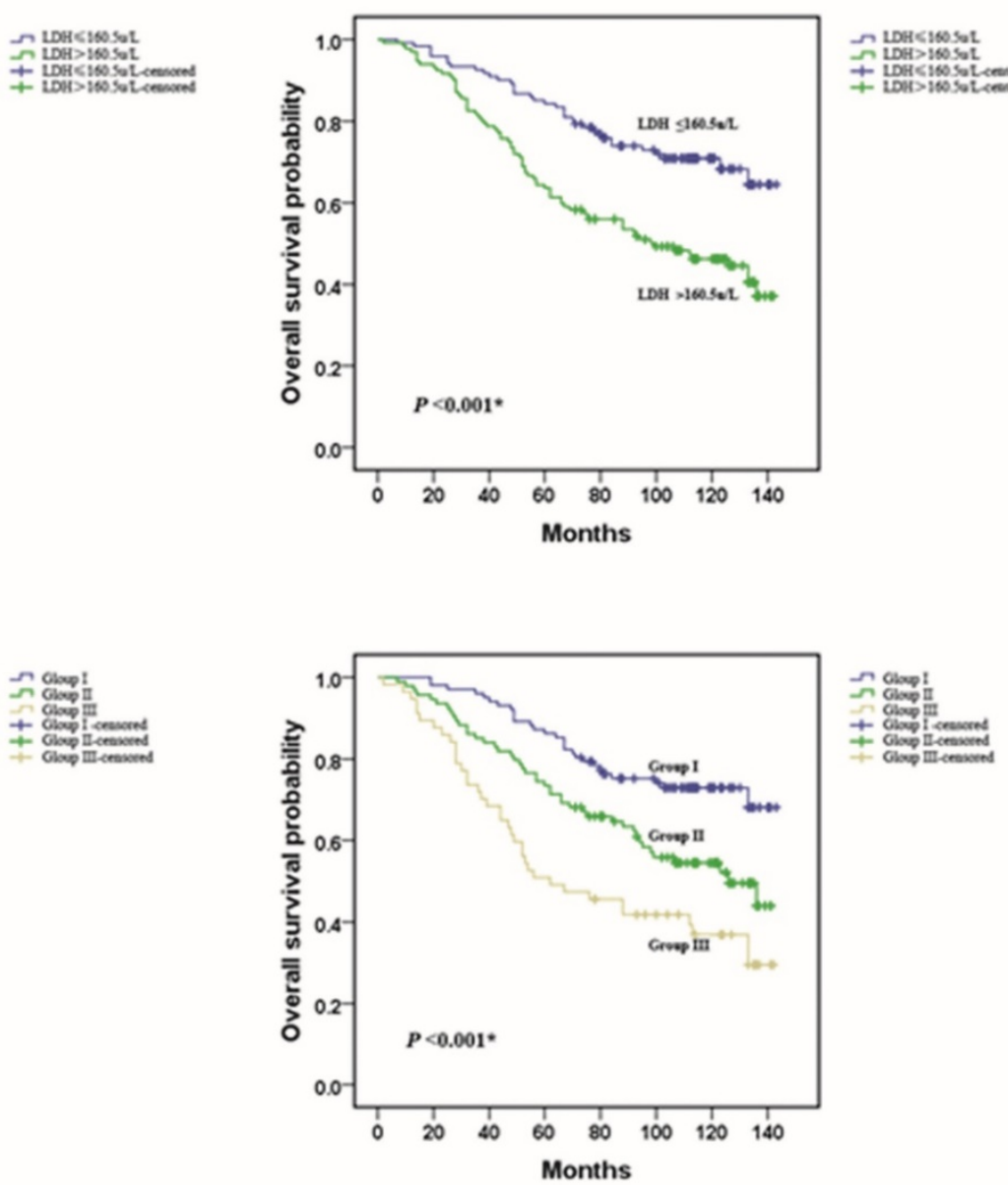

Figure 3. Prognostic value of the pre-treatment serum ALP and LDH levels in triple negative breast cancer patients. (A and D) TNBC patients with a higher level of pre-treatment ALP had a worse disease-free survival and overall survival than patients; $(B$ and $E)$ TNBC patients with a higher level of pre-treatment LDH had a worse disease-free survival and overall survival; (C and F) Group III patients(ALP>66.5 u/L and LDH>160.5 u/L) had the worst prognosis.

ALP is a nonspecific enzyme whose total serum levels reflect the combined activity of several isoenzymes found in the liver, kidney, intestinal lining and bone[24]. An electron microscopic cytochemistry study showed that in nucleolar localization ALP could indicate proliferation [25]. During the cell cycle, in the nucleolus of cancer cells, ALP activity higher and changes in localization [26]. Von Hoof et al. [27] and Steiber et al.[28] found that in non-metastatic breast cancer there are no significant differences in ALP levels. However, others have found a significant rise in ALP in metastasis [29]. Recent small-scale studies suggested that a significant increase in serum ALP was observed in breast cancer patients $[30,31]$ and it has consistently been shown to predict liver metastases[32] and bone metastases[33, 34].

It was widely recognized that a shift to aerobic 
glycolysis is a hallmark of most cancer cells[35]. LDH is a metabolic enzyme which catalyzes the interconversion of pyruvate and lactate. LDH level is increased during some important pathological process such as tissue injury, hypoxia and necrosis. In addition, various cancer cells express a higher LDH level than normal cells and the elevation of $\mathrm{LDH}$ might influent the tumor metabolism and microenvironment which may promote tumor progression [36]. Thus, the potential role of $\mathrm{LDH}$ as a prognostic biomarker in oncology has long been recognized [35, 37, 38]. A higher level of $\mathrm{LDH}$ is significantly associated with poor survival in terminal cancer patients which confirmed by several studies. $[39,40]$. In bisphosphonate-treated breast cancer patients, an analysis demonstrated that LDH levels correlate with survival in patients with bone metastases [41].

In Previous researches, it was strongly indicated the valuable prognostic roles of ALP and LDH in cancer. However, little is known about the ALP and $\mathrm{LDH}$ prognostic value in TNBC patients. In the present study, we applied receiver operating curve (ROC) analysis to calculate optimal cutoff values for the pre-treatment serum ALP or LDH level. With the highest Youden's index, the cutoff values of ALP and $\mathrm{LDH}$ in the present study were $66.5 \mathrm{u} / \mathrm{L}$ and $160.5 \mathrm{u} / \mathrm{L}$, respectively. Then, through clinical pathological features analyzing, we discovered that both of ALP and LDH expression levels were related to the age, menstrual status and LN Infiltrated. Meanwhile, LDH also associated with BMI. In survive analysis, we examined the prognostic value of pre-treatment ALP and LDH to predict the long-term outcome of TNBC patients and found that ALP and $\mathrm{LDH}$ were independent predictors for DFS and OS. What's more, patients with ALP $>66.5 \mathrm{u} / \mathrm{L}$ and $\mathrm{LDH}>160.5 \mathrm{u} / \mathrm{L}$ had the worst DFS and OS. Univariate and multivariate regression analyses confirmed ALP levels and LDH levels were independent unfavorable prognostic factors for DFS and OS in TNBC patients. Synthesize the above results, this study currently represents the first one evaluating the prognostic value of pre-treatment ALP and LDH levels in TNBC patients.

We must acknowledge that there are several limitations in our analysis which connected to its retrospective design. First, the data were obtained from a single institution. In addition, there may have been a lack of uniformity because enrolled patients not received a unified treatment which may influence patients' survival. In recent studies, depending on the gene expression profile, TNBC can be classified into seven subtypes and the different subtypes are different sensitivities to treatment [42, 43]. Further prospective studies are therefore warranted to confirm these preliminary results and to investigate the correlations between TNBC subtypes and the serum levels of ALP and LDH.

In conclusion, our present study demonstrated that the pre-treatment serum ALP and LDH levels are independent prognostic factors for predicting the outcomes for TNBC patients. It may help clinicians to assess the risks of relapse and death in TNBC patients. In the future, the value and the most sensitive cut-off points of serum ALP and LDH required large clinical trials to determine.

\section{Abbreviations}

ALP, alkaline phosphatase; LDH, lactate dehydrogenase; TNBC, triple negative breast cancer; ROC, receiver operating curve; DFS, disease-free survival; OS, overall survival; NLR, neutrophil to lymphocyte ratio; ER, estrogen receptor; PR, progesterone receptor; Her 2, human epidermal growth factor receptor 2; IHC, immunohistochemistry; AJCC, American Joint Committee on Cancer; TNM, tumor node metastasis; LN, lymph node; BMI, body mass index; HRs, Hazard ratios; CIs, confidence intervals; AUC, area under the receiver operating curve.

\section{Acknowledgement}

This work was supported by funds from the Science and Technology Planning Projects of Guangdong and Guangzhou (2013B060300009, 2015B020211002, 2014A020212079 and 2015B090901050 to X. Xie; 2013B021800072 to W. Wei; 2014J4100169 to H. Tang), the Guangdong Natural Science Foundation (S2012010008521 to W. Wei) and the National Natural Science Foundation of China (81272514, 81472575 and 81372133to X. Xie; 81472469 to $\mathrm{H}$. Tang).

\section{Conflicts of Interest}

No interest to disclose.

\section{References}

1. Siegel RL, Miller KD, Jemal A. Cancer statistics, 2015. CA: a cancer journal for clinicians. 2015; 65: 5-29.

2. Zheng $\mathrm{R}$, Zeng $\mathrm{H}$, Zhang $\mathrm{S}$, Chen $\mathrm{T}$, Chen $\mathrm{W}$. National estimates of cancer prevalence in China, 2011. Cancer letters. 2015

3. Dent R, Trudeau M, Pritchard KI, Hanna WM, Kahn HK, Sawka CA, et al. Triple-negative breast cancer: clinical features and patterns of recurrence. Clinical cancer research : an official journal of the American Association for Cancer Research. 2007; 13: 4429-34.

4. Bauer KR, Brown M, Cress RD, Parise CA, Caggiano V. Descriptive analysis of estrogen receptor (ER)-negative, progesterone receptor (PR)-negative, and HER2-negative invasive breast cancer, the so-called triple-negative phenotype: a population-based study from the California cancer Registry. Cancer. 2007; 109: 1721-8.

5. Pistelli M, De Lisa M, Ballatore Z, Caramanti M, Pagliacci A, Battelli N, et al. Pre-treatment neutrophil to lymphocyte ratio may be a useful tool in predicting survival in early triple negative breast cancer patients. BMC cancer. 2015; 15: 195. 
6. Wen J, Yang Y, Ye F, Huang X, Li S, Wang Q, et al. The preoperative plasma fibrinogen level is an independent prognostic factor for overall survival of breast cancer patients who underwent surgical treatment. Breast. 2015; 24: $745-50$.

7. Maisano R, Azzarello D, Del Medico P, Maisano M, Bottari M, Egitto G, et al. Alkaline phosphatase levels as a prognostic factor in metastatic colorectal cancer treated with the FOLFOX 4 regimen: a monoinstitutional retrospective study. Tumori. 2011; 97: 39-42.

8. Xie Y, Wei ZB, Duan XW. Prognostic value of pretreatment serum alkaline phosphatase in nasopharyngeal carcinoma. Asian Pacific journal of cancer prevention : APJCP. 2014; 15: 3547-53.

9. Sonpavde G, Pond GR, Berry WR, de Wit R, Armstrong AJ, Eisenberger MA, et al. Serum alkaline phosphatase changes predict survival independent of PSA changes in men with castration-resistant prostate cancer and bone metastasis receiving chemotherapy. Urologic oncology. 2012; 30: 607-13.

10. Wei XL, Zhang DS, He MM, Jin Y, Wang DS, Zhou YX, et al. The predictive value of alkaline phosphatase and lactate dehydrogenase for overall survival in patients with esophageal squamous cell carcinoma. Tumour biology : the journal of the International Society for Oncodevelopmental Biology and Medicine. 2016; 37: 1879-87.

11. Wei Z, Zeng X, Xu J, Duan X, Xie Y. Prognostic value of pretreatment serum levels of lactate dehydrogenase in nonmetastatic nasopharyngeal carcinoma: single-site analysis of 601 patients in a highly endemic area. OncoTargets and therapy. 2014; 7: 739-49.

12. Huang JJ, Cai MY, Ye S, Li ZM, Huang HQ, Lin TY. [Clinical analysis of 19 cases of subcutaneous panniculitis T-cell lymphoma with literature review]. Ai zheng $=$ Aizheng $=$ Chinese journal of cancer. 2009; 28: 1093-9.

13. Sagman U, Feld R, Evans WK, Warr D, Shepherd FA, Payne D, et al. The prognostic significance of pretreatment serum lactate dehydrogenase in patients with small-cell lung cancer. Journal of clinical oncology : official journal of the American Society of Clinical Oncology. 1991; 9: 954-61.

14. Eleutherakis-Papaiakovou V, Bamias A, Gika D, Simeonidis A, Pouli A, Anagnostopoulos A, et al. Renal failure in multiple myeloma: incidence, correlations, and prognostic significance. Leukemia \& lymphoma. 2007; 48: $337-41$

15. Yamada Y, Nakamura K, Aoki S, Tobiume M, Zennami K, Kato Y, et al. Lactate dehydrogenase, Gleason score and HER-2 overexpression are significant prognostic factors for M1b prostate cancer. Oncology reports. 2011; 25: 937-44.

16. Foulkes WD, Smith IE, Reis-Filho JS. Triple-negative breast cancer. The New England journal of medicine. 2010; 363: 1938-48.

17. Jia W, Wu J, Jia H, Yang $Y$, Zhang X, Chen K, et al. The Peripheral Blood Neutrophil-To-Lymphocyte Ratio Is Superior to the Lymphocyte-To-Monocyte Ratio for Predicting the Long-Term Survival of Triple-Negative Breast Cancer Patients. PloS one. 2015; 10: e0143061.

18. Azab B, Bhatt VR, Phookan J, Murukutla S, Kohn N, Terjanian T, et al. Usefulness of the neutrophil-to-lymphocyte ratio in predicting short- and long-term mortality in breast cancer patients. Annals of surgical oncology. 2012; 19: 217-24

19. Wen J, Ye F, Huang X, Li S, Yang L, Xiao X, et al. Prognostic Significance of Preoperative Circulating Monocyte Count in Patients With Breast Cancer: Based on a Large Cohort Study. Medicine. 2015; 94: e2266.

20. Krenn-Pilko S, Langsenlehner U, Thurner EM, Stojakovic T, Pichler M, Gerger A, et al. The elevated preoperative platelet-to-lymphocyte ratio predicts poor prognosis in breast cancer patients. British journal of cancer. 2014; 110: 2524-30.

21. Krenn-Pilko S, Langsenlehner U, Stojakovic T, Pichler M, Gerger A, Kapp KS, et al. An elevated preoperative plasma fibrinogen level is associated with poor disease-specific and overall survival in breast cancer patients. Breast. 2015; 24: $667-72$.

22. Tabassum U, Reddy O, Mukherjee G. Elevated serum haptoglobin is associated with clinical outcome in triple-negative breast cancer patients. Asian Pacific journal of cancer prevention : APJCP. 2012; 13: 4541-4.

23. Sicking I, Edlund K, Wesbuer E, Weyer V, Battista MJ, Lebrecht A, et al. Prognostic influence of pre-operative C-reactive protein in node-negative breast cancer patients. PloS one. 2014; 9: e111306.

24. Harris $\mathrm{H}$. The human alkaline phosphatases: what we know and what we don't know. Clinica chimica acta; international journal of clinical chemistry. 1990; 186: 133-50.

25. Yamamoto K, Awogi T, Okuyama K, Takahashi N. Nuclear localization of alkaline phosphatase in cultured human cancer cells. Medical electron microscopy : official journal of the Clinical Electron Microscopy Society of Japan. 2003; 36: 47-51.

26. Xu XS, Miao RC, Zhang LQ, Wang RT, Qu K, Pang Q, et al. Model Based on Alkaline Phosphatase and Gamma-Glutamyltransferase for Gallbladder Cancer Prognosis. Asian Pacific journal of cancer prevention : APJCP. 2015; 16 : $6255-9$

27. Van Hoof VO, Van Oosterom AT, Lepoutre LG, De Broe ME. Alkaline phosphatase isoenzyme patterns in malignant disease. Clinical chemistry. 1992; 38: 2546-51.

28. Stieber P, Nagel D, Ritzke C, Rossler N, Kirsch CM, Eiermann W, et al. Significance of bone alkaline phosphatase, CA 15-3 and CEA in the detection of bone metastases during the follow-up of patients suffering from breast carcinoma. European journal of clinical chemistry and clinical biochemistry : journal of the Forum of European Clinical Chemistry Societies. 1992; 30: $809-14$.
29. Ramaswamy G, Rao VR, Krishnamoorthy L, Ramesh G, Gomathy R, Renukadevi D. Serum levels of bone alkaline phosphatase in breast and prostate cancers with bone metastasis. Indian journal of clinical biochemistry : IJCB. 2000; 15: 110-3.

30. Mishra S, Sharma DC, Sharma P. Studies of biochemical parameters in breast cancer with and without metastasis. Indian journal of clinical biochemistry : IJCB. 2004; 19: 71-5.

31. Choudhari A, Desai P, Indumati V, Kadi S. Activities of serum Ada, GGT and alp in carcinoma breast-a case control study for diagnostic and prognostic significance. Indian journal of medical sciences. 2013; 67: 123-9.

32. Kim JM, Kwon CH, Joh JW, Park JB, Ko JS, Lee JH, et al. The effect of alkaline phosphatase and intrahepatic metastases in large hepatocellular carcinoma. World journal of surgical oncology. 2013; 11: 40.

33. Han KS, Hong SJ. Serum alkaline phosphatase differentiates prostate-specific antigen flare from early disease progression after docetaxel chemotherapy in castration-resistant prostate cancer with bone metastasis. Journal of cancer research and clinical oncology. 2014; 140: 1769-76.

34. Du WX, Duan SF, Chen JJ, Huang JF, Yin LM, Tong PJ. Serum bone-specific alkaline phosphatase as a biomarker for osseous metastases in patients with malignant carcinomas: a systematic review and meta-analysis. Journal of cancer research and therapeutics. 2014; 10 Suppl: C140-3.

35. Augoff K, Hryniewicz-Jankowska A, Tabola R. Lactate dehydrogenase 5: an old friend and a new hope in the war on cancer. Cancer letters. 2015; 358: 1-7.

36. Han X, Sheng X, Jones HM, Jackson AL, Kilgore J, Stine JE, et al. Evaluation of the anti-tumor effects of lactate dehydrogenase inhibitor galloflavin in endometrial cancer cells. Journal of hematology \& oncology. 2015; 8: 2 .

37. Le Scodan R, Massard C, Jouanneau L, Coussy F, Gutierrez M, Kirova Y, et al. Brain metastases from breast cancer: proposition of new prognostic score including molecular subtypes and treatment. Journal of neuro-oncology. 2012; 106: 169-76.

38. Nieder C, Dalhaug A, Haukland E, Mannsaker B, Pawinski A. Tumor marker analyses in patients with brain metastases: patterns of practice and implications for survival prediction research. Tumour biology : the journal of the International Society for Oncodevelopmental Biology and Medicine. 2015; 36: 6471-6.

39. Passardi A, Scarpi E, Tamberi S, Cavanna L, Tassinari D, Fontana A, et al. Impact of Pre-Treatment Lactate Dehydrogenase Levels on Prognosis and Bevacizumab Efficacy in Patients with Metastatic Colorectal Cancer. PloS one. 2015; 10: e0134732

40. Scartozzi M, Giampieri R, Maccaroni E, Del Prete M, Faloppi L, Bianconi M, et al. Pre-treatment lactate dehydrogenase levels as predictor of efficacy of first-line bevacizumab-based therapy in metastatic colorectal cancer patients. British journal of cancer. 2012; 106: 799-804.

41. Brown JE, Cook RJ, Lipton A, Coleman RE. Serum lactate dehydrogenase is prognostic for survival in patients with bone metastases from breast cancer: a retrospective analysis in bisphosphonate-treated patients. Clinical cancer research : an official journal of the American Association for Cancer Research. 2012; 18: 6348-55.

42. Lehmann BD, Bauer JA, Chen X, Sanders ME, Chakravarthy AB, Shyr Y, et al. Identification of human triple-negative breast cancer subtypes and preclinical models for selection of targeted therapies. The Journal of clinical investigation. 2011; 121: 2750-67.

43. Metzger-Filho O, Tutt A, de Azambuja E, Saini KS, Viale G, Loi S, et al. Dissecting the heterogeneity of triple-negative breast cancer. Journal of clinical oncology : official journal of the American Society of Clinical Oncology. 2012; 30: $1879-87$ 